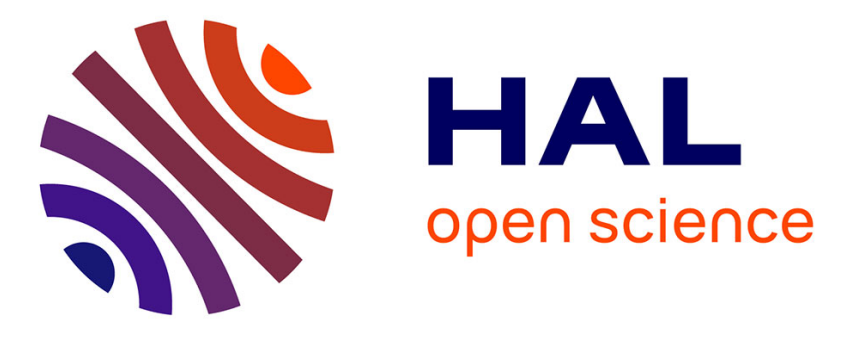

\title{
Mono-Versus Poly-Crystalline SiC for Nuclear Applications
}

Xian Huang, Taguhi Yeghoyan, Stéphane Gavarini, Véronique Soulière, Nathalie Millard-Pinard, Gabriel Ferro

\section{- To cite this version:}

Xian Huang, Taguhi Yeghoyan, Stéphane Gavarini, Véronique Soulière, Nathalie Millard-Pinard, et al.. Mono-Versus Poly-Crystalline SiC for Nuclear Applications. International Conference on Silicon Carbide and Related Materials, Sep 2019, Kyoto, Japan. pp.139-144, 10.4028/www.scientific.net/MSF.1004.139 . hal-02990900

\section{HAL Id: hal-02990900 https://hal.science/hal-02990900}

Submitted on 24 Nov 2020

HAL is a multi-disciplinary open access archive for the deposit and dissemination of scientific research documents, whether they are published or not. The documents may come from teaching and research institutions in France or abroad, or from public or private research centers.
L'archive ouverte pluridisciplinaire HAL, est destinée au dépôt et à la diffusion de documents scientifiques de niveau recherche, publiés ou non, émanant des établissements d'enseignement et de recherche français ou étrangers, des laboratoires publics ou privés. 


\title{
Mono- versus poly-crystalline SiC for nuclear applications
}

\author{
HUANG Xian ${ }^{1}$, YEGHOYAN Taguhi ${ }^{2}$, GAVARINI Stéphane ${ }^{1, a}$, SOULIERE \\ Véronique $^{2, \mathrm{~b}}$, MILLARD-PINARD Nathalie ${ }^{1, \mathrm{c}}$, FERRO Gabriel $^{2, \mathrm{~d}^{*}}$ \\ ${ }^{1)}$ Institut de Physique Nucléaire de Lyon, UMR CNRS 5822, Université de Lyon (UDL), \\ Lyon 1 University, 69622 Villeurbanne (France) \\ 2) Laboratoire des Multimatériaux et Interfaces, UMR CNRS 5615, Université de Lyon (UDL), \\ Lyon 1 University, 69622 Villeurbanne (France) \\ agavarini@ipnl.in2p3.fr, ${ }^{b}$ veronique.souliere@univ-lyon1.fr, 'cmillard@ipnl.in2p3.fr, \\ dgabriel.ferro@univ-lyon1.fr
}

Keywords: Implantation, Xenon, 3C-SiC, polycrystal, monocrystal, amorphization, nuclear

\begin{abstract}
C-SiC layers of different microstructures (monocrystalline (100) and (111) oriented and polycrystalline) were implanted with high energy $(800 \mathrm{keV}){ }^{129} \mathrm{Xe}^{++}$ions. Implantations were performed at room temperature (RT) and at $500{ }^{\circ} \mathrm{C}$ using two different fluences of $\Phi_{1}=1 \times 10^{16}$ and $\Phi_{2}=1 \times 10^{17} \mathrm{at} / \mathrm{cm}^{2}$. Surface blistering was only observed for RT and $\Phi_{2}$ implantations into poly-SiC material while mono-SiC kept rather smooth surface. This was due to more homogeneous Xe bubbles distribution (200 nm deep) in the mono-SiC than in the poly-SiC. Xe retention was found to be almost complete for all samples. Some Xe enhanced diffusion was detected in the poly-SiC material which was attributed to grain boundaries. Some irradiation-induced oxidation effect was evidenced, O element being located at the depth where Xe bubbles are accumulating. This was more pronounced for poly than for mono-SiC. These results demonstrate that $\mathrm{SiC}$ microstructure affects many aspects of its behavior upon Xe irradiation.
\end{abstract}

\section{Introduction}

Silicon carbide is an important material for nuclear reactor conceptions due to its good thermal and mechanical properties, oxidation resistance and low neutron activation rates. It is commonly envisaged as oxidation protection cladding placed around the uranium fuel [1-3] or as tritium permeation barrier coatings for fusion reactors [4-5]. Xenon is an abundant fission product, insoluble in many materials and prompt to create gas bubbles. The damage production in SiC (displacement per atom - DPA) during atomic irradiation was largely investigated in the last three decades. Nevertheless, there is a lack of data on the formation of bubbles and/or cavities resulting from the incorporation and agglomeration of heavy noble gas atoms produced during fission and alpha-decay of actinides. In fact, it has been shown that the creation of bubbles/cavities induces deleterious effects on the physical integrity of $\mathrm{SiC}$ (e.g. formation of cracks, surface swelling and exfoliation). It is thus essential to study $\mathrm{SiC}$ behavior under irradiation of such heavy element especially in terms of Xe retention, amorphization and material swelling. Few studies have examined the behavior of $\mathrm{Xe}$ in $\mathrm{SiC}$ [6-10] but the effect of $\mathrm{SiC}$ crystalline microstructure on such irradiation behavior is not completely understood, especially at high fluence. This is the main target of the present work.

\section{Experimental}

3C-SiC samples with three different microstructures were elaborated and subjected to high $\mathrm{Xe}$ fluence: 1) single-crystalline 3C-SiC(100), 2) single-crystalline 3C-SiC(111) and 3) polycrystalline 3C-SiC. Most of the results will concern the mono-SiC(100) and poly-SiC samples while comparison with mono-SiC(111) will be done punctually with preliminary results. All materials were grown on Si substrate by chemical vapour deposition (CVD) using standard 
$\mathrm{SiH}_{4} / \mathrm{C}_{3} \mathrm{H}_{8} / \mathrm{H}_{2}$ gas mixture. For the single-crystalline cases, standard two-step CVD process (carbonization at $1165^{\circ} \mathrm{C}+$ epitaxy at $1350^{\circ} \mathrm{C}$ under $\mathrm{C} / \mathrm{Si}$ ratio of 4.5 ) was used. $\mathrm{Si}(100)$ and $\mathrm{Si}(111)$ substrates were used to obtain $\sim 3 \mu \mathrm{m}$ thick $3 \mathrm{C}$-SiC layers with the heteroepitaxial orientation. For the poly-crystalline case (poly-SiC), the $\mathrm{Si}(100)$ substrate was carbonized 10 min at $1000^{\circ} \mathrm{C}$ after which $\sim 2 \mu \mathrm{m}$ thick $\mathrm{SiC}$ deposition was performed at the same temperature under $\mathrm{C} / \mathrm{Si}$ ratio of 15 .

These samples were implanted by $800 \mathrm{keV}^{129} \mathrm{Xe}^{++}$at two different fluences of $\Phi_{1}=1 \times 10^{16}$ and $\Phi_{2}=1 \times 10^{17} \mathrm{at} / \mathrm{cm}^{2}$, at room temperature (RT) and at $500{ }^{\circ} \mathrm{C}$. The incident angle was set to $1^{\circ}$ to avoid canalization effect in the case of single-crystals. SRIM-2013 simulation was used to estimate the resulting Xe concentrations and DPA profiles from these experimental conditions (see Fig.1). It shows that the mean range of Xe penetration is $\sim 208 \mathrm{~nm}$ with $47 \mathrm{~nm}$ of straggling. The maximal Xe concentrations are 0.84 and 7.79 at $\%$ at $208 \mathrm{~nm}$ for $\Phi_{1}$ and $\Phi_{2}$ fluences respectively. The microstructure evolution was analyzed by electron microscopy techniques (scanning (SEM) and transmission (TEM)) and their elemental composition was assessed by Rutherford Backscattering spectrometry (RBS) and Energy Dispersive Spectroscopy (EDS). RBS was operated using either $2.5 \mathrm{MeV} \alpha$-particles or $1 \mathrm{MeV}$ proton for composition and thickness determination.

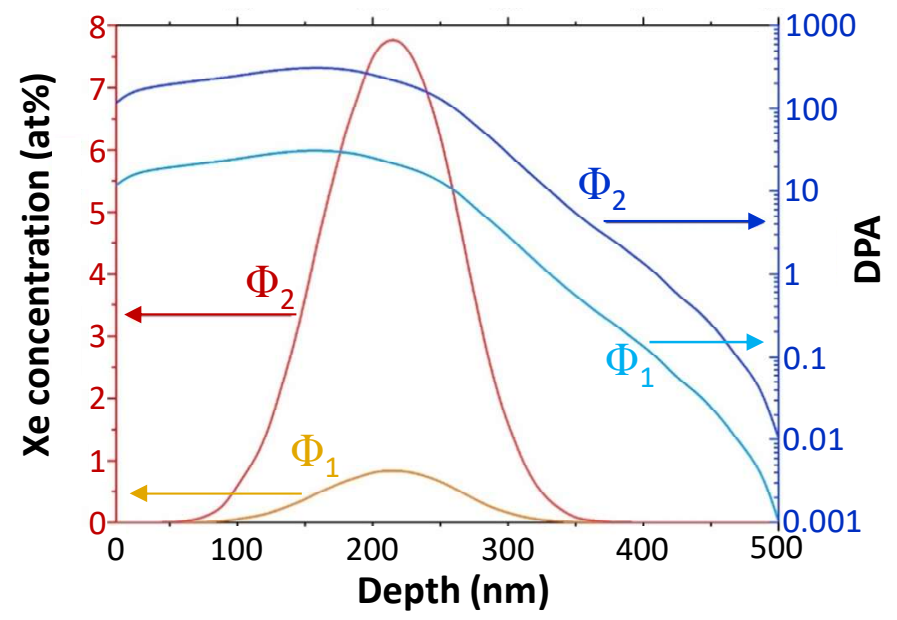

Figure 1. Xe concentration and DPA profiles calculated from SRIM-2013 simulations for RT irradiations of $3 \mathrm{C}$-SiC using $800 \mathrm{keV}{ }^{129} \mathrm{Xe}^{++}$ fluences of $\Phi_{1}=1 \times 10^{16}$ and $\Phi_{2}=$ $1 \times 10^{17} \mathrm{at} / \mathrm{cm}^{2}$.

\section{Results and discussion}

The as-grown surface morphologies of the three kinds of 3C-SiC layers are shown in Fig. 2. The monocrystalline layers show the standard features of heteroepitaxial films while the polycrystalline film is composed of a dense agglomeration of nano-size 3C-SiC grains (of $\sim 10-15 \mathrm{~nm}$ diameter according to HR-TEM observations and X-Ray Diffraction data using Debye-Scherrer equation, not shown).
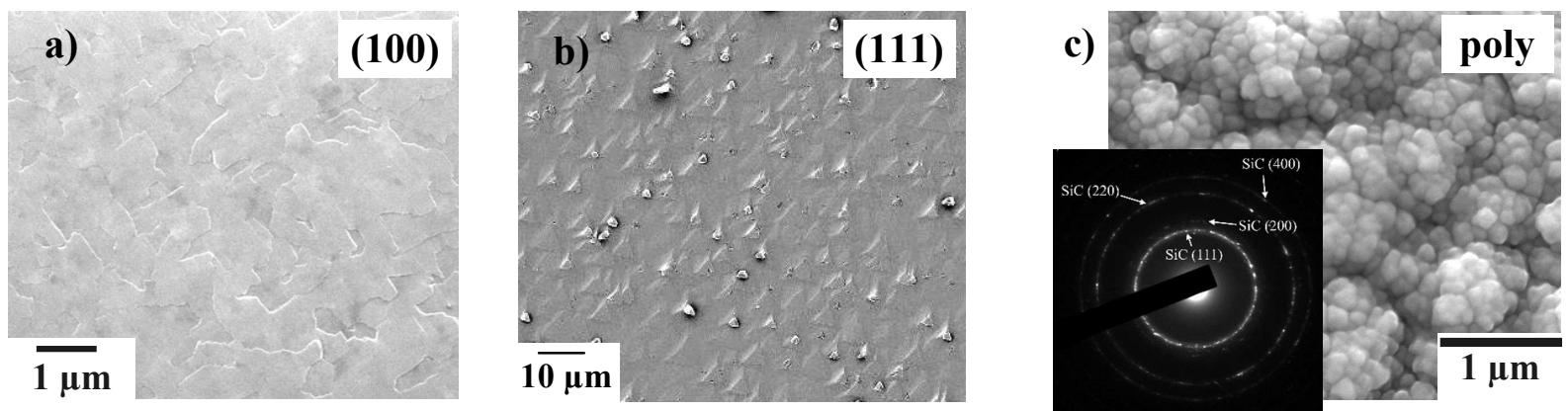

Figure 2. Surface morphology of as-grown 3C-SiC layers: monocrystalline a) (100) and b) (111) oriented and c) polycrystalline (insert is the SAED pattern recorded on this poly-SiC). 
Figure 3 shows the evolution of the surface morphology for the mono-SiC(100) and poly$\mathrm{SiC}$ samples after Xe irradiation at lower fluence $\Phi_{1}$. Observations performed at the limit of implantation zones allow easier differentiation of the effect of this implantation. One can see that the morphology is preserved upon irradiation at $500^{\circ} \mathrm{C}$ while at $\mathrm{RT}$ some smoothening can be observed on the irradiated area (better seen on the poly-SiC sample), probably due to surface erosion by the impinging heavy ions and also material amorphization (critical dose at RT near 0.35 DPA according to [6]). For higher fluence $\Phi_{2}$, Xe irradiation at $500^{\circ} \mathrm{C}$ does not modify significantly the surface morphology, alike for the lower fluence case (Fig. 4).

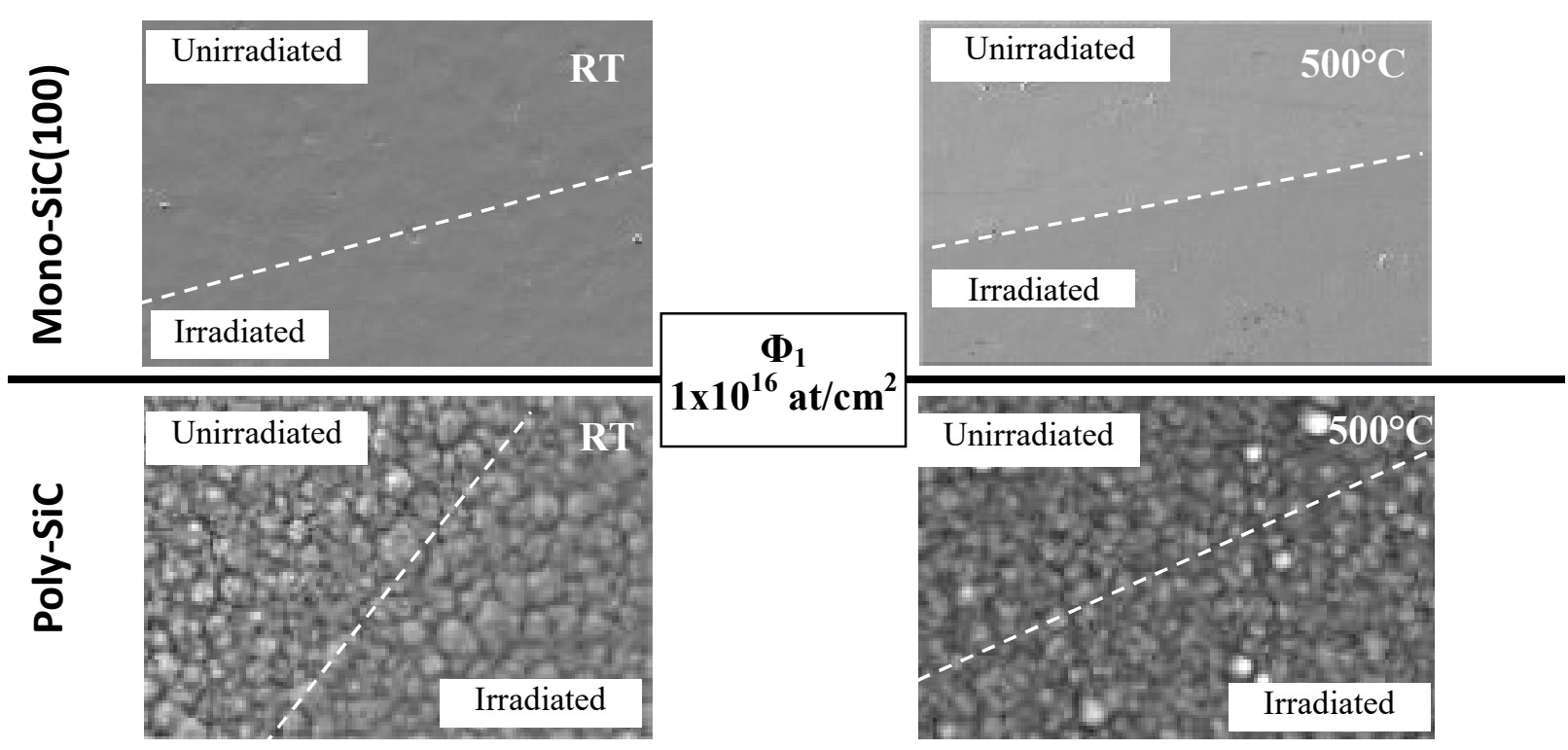

Figure 3. Evolution of the surface morphology of mono-SiC(100) (up) and poly-SiC (down) layers after Xe irradiation with $\Phi_{1}$ fluence at RT (left) and $500^{\circ} \mathrm{C}$ (right). The dotted lines correspond to the boundary between the unirradiated and the irradiated areas.

The main difference came from RT irradiations which led to the formation of wavy lines between surface blisters on poly-SiC sample while some smoothening is observed on both mono-SiC (100) and (111) samples under the same conditions (see Fig. 5). Nano-size bubbles are formed at $\sim 200 \mathrm{~nm}$ beneath the surface in both cases, as indicated by TEM cross-section observations (see Fig. 5). This depth value is in accordance with the maximum peak concentration obtained by SRIM simulations (Fig. 1). The bubbles distribution is more homogeneous for the mono-SiC material, in which they form a regular $\sim 200 \mathrm{~nm}$ thick band, than for the poly-SiC material in which deformations occurs beneath each blister, accentuating surface roughness. This is probably at the origin of the blistering effect observed on the poly-SiC.

As a result, the $\mathrm{SiC}$ microstructure and surface morphology play an obvious role in the Xe induced swelling mechanism. At $\mathrm{RT}$, disordered $\mathrm{SiC}$ material is more prone to bubble aggregation and thus surface deformation than crystalline $\mathrm{SiC}$, despite the fact that both materials were amorphized under the irradiation conditions. Note also that the total amorphized depth seems to be higher for the mono-SiC $(\sim 580 \mathrm{~nm})$ than for the poly-SiC $(\sim 410 \mathrm{~nm})$ layer even though the presence of the blisters renders difficult such depth determination. This difference could be partially due to some residual channeling effect in the mono-SiC case (before material amorphization) despite the $\mathrm{Xe}^{++}$beam incidence angle of $1^{\circ}$ used. 


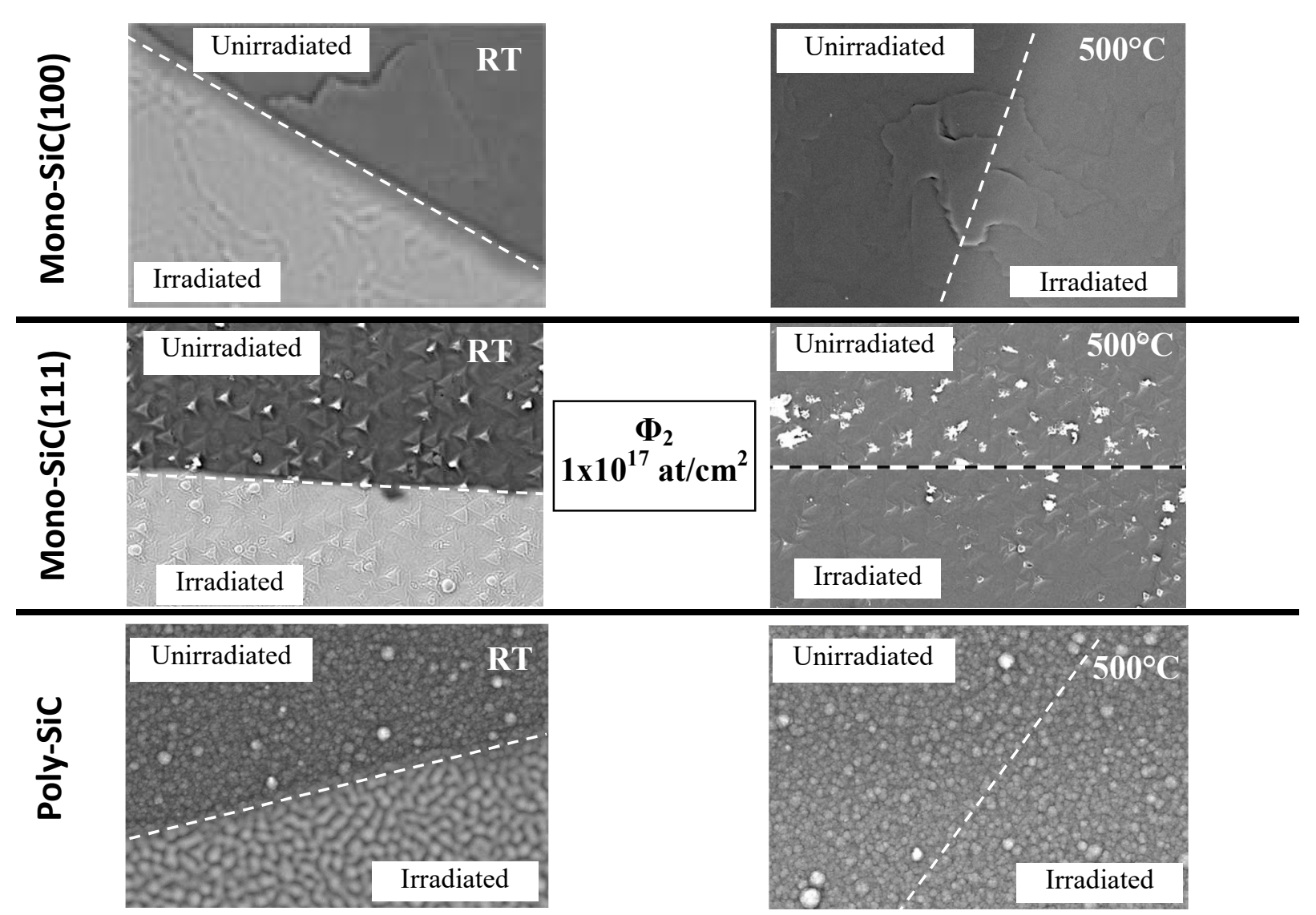

Figure 4. Evolution of the surface morphology of mono-SiC(100), mono-SiC(111) and polySiC layers after Xe irradiation with $\Phi_{2}$ fluence at RT (left) and $500^{\circ} \mathrm{C}$ (right). The dotted lines correspond to the boundary between the unirradiated and the irradiated areas.

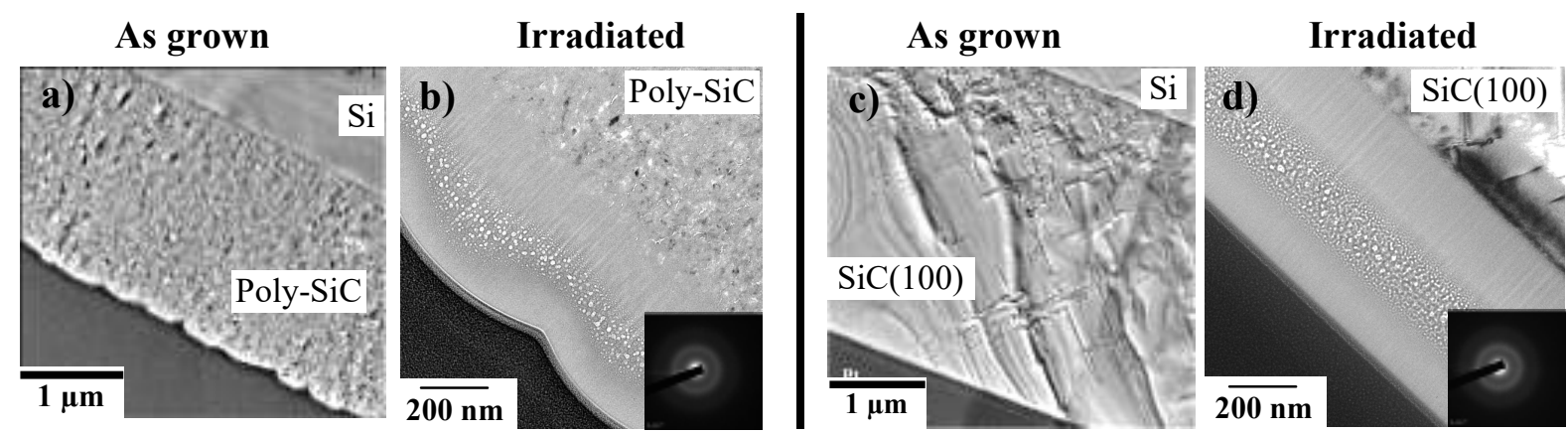

Figure 5: TEM micrographs recorded on poly-SiC ((a) and b)) and mono-SiC(100) samples ((c) and d)) both as grown and after irradtiation at RT under high Xe fluence $\Phi_{2}$. Inserts in b) and d) show SAED patterns recorded on the implanted zone of the respective samples.

Xe retention inside the irradiated samples (at low fluence $\Phi_{1}$ ) was studied using RBS elemental depth profile (Fig. 6). In addition to the expected $\mathrm{C}, \mathrm{Si}$, and $\mathrm{Xe}$ elements, some traces of $\mathrm{O}$ were detected on all samples. When comparing with SRIM simulations, Xe retention inside $\mathrm{SiC}$ in all samples is estimated to be almost $100 \%$. In the inserts showing a zoom on the Xe peaks areas, one can see no difference for RT irradiation between poly and mono-SiC while the peaks are slightly shifted for $500^{\circ} \mathrm{C}$ irradiation. One can notice a slight in-diffusion of $\mathrm{Xe}$ for the $500^{\circ} \mathrm{C}$ irradiated poly-SiC as compared with the mono-SiC $(100)$ case. This could be due to enhanced Xe diffusion through crystalline defects, especially grain boundaries. 

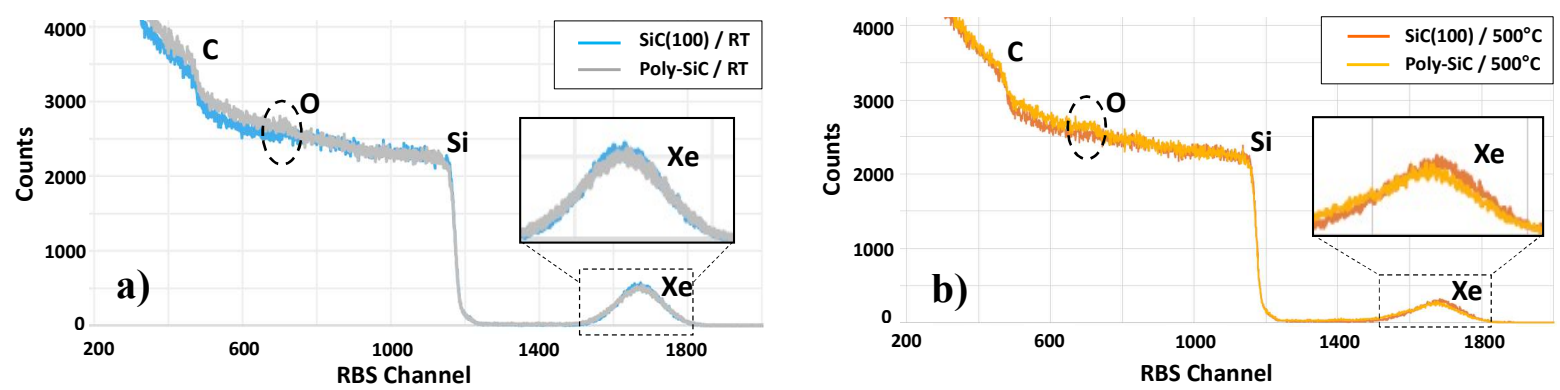

Figure 6. RBS depth profiles recorded on mono-SiC(100) and poly-SiC samples after a) RT and b) $500^{\circ} \mathrm{C} \mathrm{Xe}$ irradiations at low fluence of $\Phi_{1}$. Inserts on each figure show a zoom on the Xe peaks areas.

Coming back to $\mathrm{O}$ element, its presence was further investigated using EDS mapping recorded at the boundary between irradiated and unirradiated zones. In the case of poly-SiC sample, $500^{\circ} \mathrm{C}$ irradiation led to significant enhancement of $\mathrm{O}$ related signal on the irradiated zone (Fig. 7a). This effect is not seen for the mono-SiC(100) sample though $\mathrm{O}$ is detected in small amount on both side of the irradiation limit (Fig. 7b).

a)

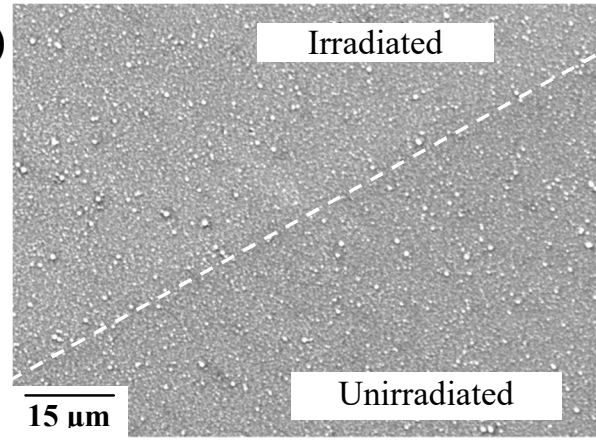

c)

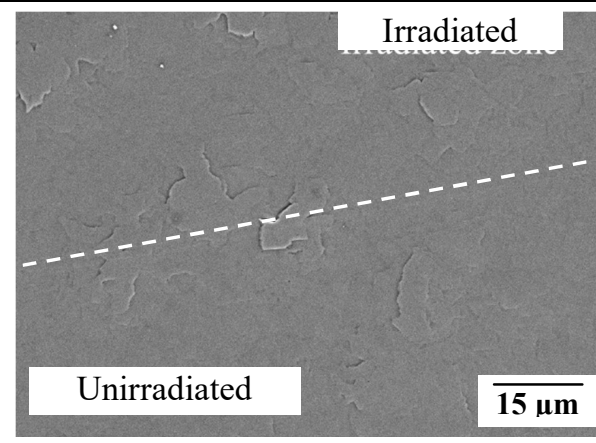

b)
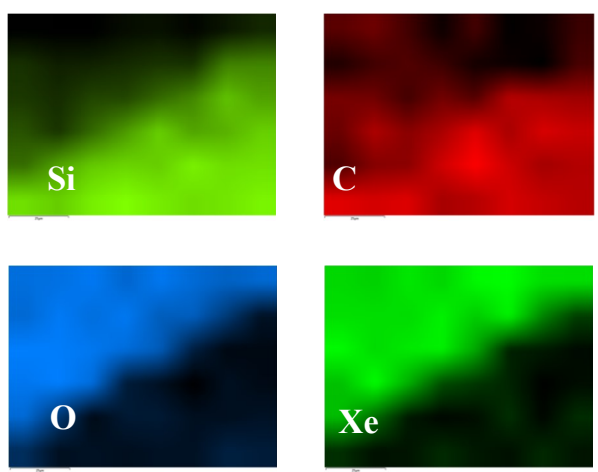

d)

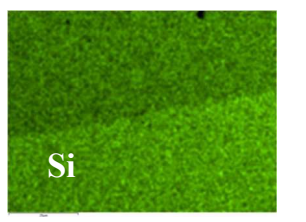

Xe
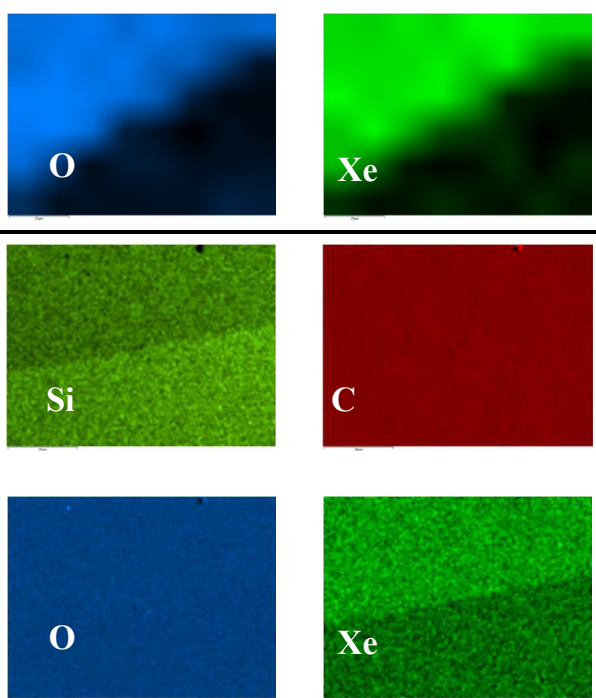

Figure 7: SEM image after irradiation at $500^{\circ} \mathrm{C}$ under low Xe fluence $\Phi_{1}$ of a) poly-SiC and c) mono-SiC(100) layer surface, observed at the boundary area between irradiated and unirradiated zones. b) and d) show EDS mapping of $\mathrm{Si}, \mathrm{C}, \mathrm{O}$ and $\mathrm{Xe}$ elements on the same area as in a) and c) respectively.

STEM analyses performed on a cross-section of poly-SiC irradiated a $\mathrm{t}$ RT show that some $\mathrm{O}$ is systematically detected inside the implanted layers, spatially located at the Xe bubbles formation depth (Fig. 8). The same observation can be made on mono-SiC(100) but with less $\mathrm{O}$ intensity (not shown), which could explain why we do not see this effect in EDS mapping on mono-SiC.

As a matter of fact, this $\mathrm{O}$ is correlated to the presence of the Xe bubbles. One may argue about irradiation-induced oxidation effect occurring during or after the irradiation. Similar 
oxidation was observed in the case of $\mathrm{H}$ implanted $4 \mathrm{H}-\mathrm{SiC}$ crystals and was tentatively explained by migration of gaseous $\mathrm{O}_{2}$ or $\mathrm{H}_{2} \mathrm{O}$ from the edge of the samples through the buried defected layer [11]. This point obviously requires further investigations to be fully understood.

a)

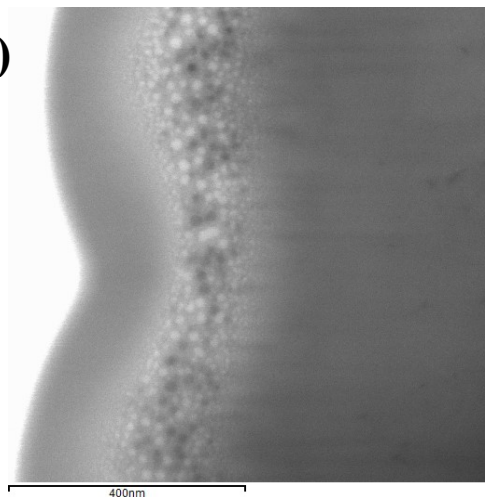

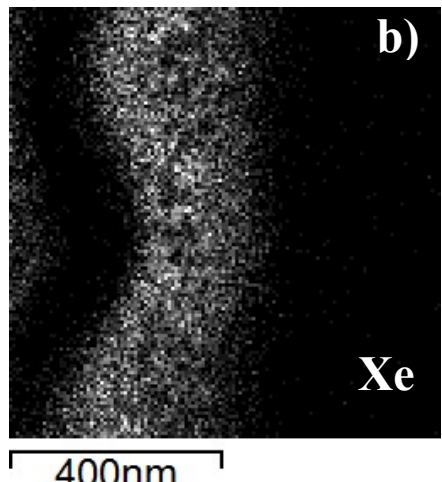

400nm

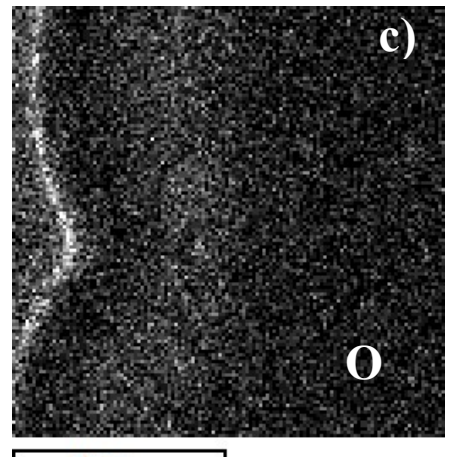

$400 \mathrm{~nm}$

Figure 8. a) TEM cross section of RT irradiated poly-SiC under $\Phi_{2}$; STEM-EDX mapping showing the repartition of b) Xe and c) O elements on the area observed in a).

\section{Summary}

This study demonstrated that the microstructure of 3C-SiC material affects many aspects of its behavior upon Xe irradiation. Disordered 3C-SiC favors Xe diffusion while being more prone to surface blistering. No significant difference was noticed between (100) and (111) oriented crystalline materials. Xe retention was found to be almost complete for all samples. Some irradiation-induced oxidation was observed.

\section{Reference}

[1] M. Zabiégo, C. Sauder, C. Lorette, P. Guédene, CEA patent, WO2013017621 A vol. 1, (2013)

[2] W.-J. Kim, D. Kim, J. Y. Park, Nucl. Engin. \& Technol. vol. 45, no 4, (2013) 565-572.

[3] Y. Katoh, L. L. Snead, T. Cheng, C. Shih, W. D. Lewis, T. Koyanagi, T. Hinoki, C. H. Henager Jr, M. Ferraris, J. Nucl. Mater. 448 (2014) 497.

[4] G. M. Wright, M.G. Durett, K.W. Hoover, D.G. Whyte, L.A. Kesler et al., J. of Nucl. Mater., 458 (2015) 272

[5] Y. Yamamoto, Y. Murakami, H. Yamaguchi, T. Yamamoto, D. Yonetsu, K. Noborio, S. Konishic, Fusion Engineering and Design 109-111 (2016) 1286-1290

[6] J. Baillet, S. Gavarini, N. Millard-Pinard, et al., J Nuclear Materials 503 (2018) 140-150

[7] C. Jiang, J. Nicolaï, A. Declémy, E. Gilabert, M.-F. Beaufort, J.-F. Barbot, Nuclear Instr. \& Methods in Phys. Res. B 374 (2016) 71-75

[8] L.L. Snead, T. Nozawa, Y. Katoh, T.S. Byun, J. Nuclear Mater. vol. 371, no 1-3, (2007) 329-377.

[9] C. Jiang, A Declémy, M-F Beaufort, A Boulle, J-F Barbot, IOP Conf. Series: Journal of Physics: Conf. Series 1190 (2019) 012015

[10] T.T. Hlatshwayo, J.H. O’Connell, V.A Skuratov, M. Msimanga, R.J. Kuhudzai, E.G. Njoroge, J.B. Malherbe, J. Phys. D: Appl. Phys. 48 (2015) 465306

[11] A. Barcz, R. Jakieła, M. Kozubal, J. Dyczewski, G.K. Celler, Nucl. Instr. \& Methods in Phys. Res. B 365 (2015) 146-149 